\title{
O Espaço Cenográfico do Espetáculo - presença na cidade e no edifício*
}

Jorge 0. Caron

Resumo

O trabalho procura estabelecer uma definição para cenário como exclusivo do planejamento do ambiente cênico do espetáculo. Verifica-se uma duplicidade de espaços, um físico e eficiente, outro imaginário e cúmplice. Através da análise dos elementos significativos da ação cênica pode se estabelecer uma relação entre o público e a cena, no âmbito do imaginário. Verifica-se de que maneira este ambiente intervém no espaço físico, tanto urbano quanto edificado.

Descreve-se, a seguir, uma intervenção com uma linha dramática (promovida por luzes coloridas) em um ambiente arquitetônico conhecido pelo público, e suas reações diante da intervenção.

This work tries to stablish a stage design definition as exclusive of the scenic environment planning of theatre activity. We verify the existence of a double space, part of it physical and efficient and part an immaginary product of complicity. Through scenic action significative elements analysis we can stablish a stage-public relationship, in an immaginary field. Then we verify in which way this kind of environment intervenes into physical space, both urban or inside a building.

In the sequence we describe a dramatic intervention (just promoted by color lighting) into an architectural place known by the public, and the public reaction facing it.
Doutor em Arquitetura e Urbanismo pela USP 


\section{Introdução}

$\mathrm{Na}$ abordagem deste assunto, que interliga os conceitos de "cenário" e "espetáculo" é necessário determinar um recorte que torne claro o campo que queremos discutir. A própria expressão "cenário" tende a ser empregada de forma extremamente ampla adquirindo a conotação de "paisagem" quando referida a desenhos do sítio urbano, ou "simulacro" quando inserida na linguagem de estrategistas, sejam eles econômicos ou militares. Mesmo os planejadores a empregam com o sentido de "plano alternativo de produção" ou de "ação" É certo que paira nesses empregos do termo cenário conceitos encadeados de visualidade e ilusão prospectiva. Muito próximos quando se fala de possibilidades visuais de um ambiente urbano, mais remotos quando se trata de alternativas estratégicas de planejamento. Mesmo assim, sempre parecendo referir-se a imagens fixadas dentro de enquadramentos fixos. Isto se nota com certa clareza no que se refere a imagens pictorialistas do urbano ou a diagramas de hipóteses estratégicas. Em ambos se revela uma certa fixidez ilusória, seja da paisagem, seja de um processo.

Ao observar o emprego conceitual do termo cenário a partir de seu limite mais periférico, sabemos que esse é um emprego emprestado a uma idéia original que, como está expresso em sua própria forma, se refere à cena. Este termo, por sua vez, em sua origem primitiva, 'skené" tinha o significado de plataforma elevada onde se simulavam ações personificadas. Aqui se nota que a idéia de algo como um simulacro tornado visual está envolvido no conceito de cenário. Por esta razão, talvez, seja possível estender a conotação interligada de visualidade e simulação a toda uma gama de ações na forma de um conceito emprestado.

Desta maneira, o primeiro recorte que queremos fazer é tratar da questão "cenário" e de seu processo de invenção e produção, "cenografia" dentro do campo exclusivo do espetáculo, território em que o conceito tem origem. Para tanto é necessário abordar, inicialmente, determinados pressupostos que envolvem a definição de espetáculo e seu espaço específico, o que seja a ação cênica e seu público, e o papel da cenografia nesse território. Delimitado esse arco, analisaremos, suscintamente, os elementos intervenientes na ação cênica, para daí observarmos, suscintamente, a natureza da intervenção cenográfica na coisa urbana e na coisa edificada.

\section{Pressupostos}

O espetáculo é um fenômeno que se dá em determinadas condições e em situações particulares. É um evento decorrente da interação entre uma ação, que pode ser narrativa ou denotativa, e seu público. Dizer isto significa que 0 espetáculo, evento público, só acontece quando determinada ação cênica entra em contato com sua assistência, momento esse, em que se estabelece um fenômeno de intercomunicação entre ambos. Implica, também, em que a ação é fruto de um planejamento e de uma produção e que o público, nesse momento, é cúmplice da ação proposta. Esta cumplicidade significa que o público está em condiçōes de decodificar a mensagem cênica e que se estabelece entre ambos, cena e assistência, uma convenção que conta de um lado com uma linguagem cênica e de outro com a manifestação do público que tem, por sua vez, uma linguagem expressiva própria. É nestas condições, exclusivamente, que podemos definir o espetáculo. A proposição, planejamento e produção de uma ação cênica 
não tem significado como espetáculo, da mesma forma que uma simples reunião de cidadãos não conforma um público na ausência de um ato cênico.

O espetáculo é, portanto, um fenômeno do contato, uma arte da presença. Tornase, assim, distinto de outras manifestações artísticas, ou fenômenos comunicativos, cujo produto existe continuamente antes, durante e depois da fruição de seu observador, como nas artes plásticas, ou que permitem a recorrência do fruidor, como na literatura e na arquitetura. O espetáculo somente existe no momento e no tempo em que a ação cênica e seu público se defrontam, criando entre eles um ato de cumplicidade.

Se a ação cênica é um produto deliberadamente planejado a ser oferecido a um público, este entendido como um conjunto de pessoas que representa uma atenção interessada e conivente com essa ação, os elementos intervenientes dessa produção deverão ser analisados, o que faremos mais adiante. O que interessa ressaltar, agora, é que um dos fatores desse planejamento envolve o sítio, lugar em que esse encontro deverá se processar. Isto representa, para cada espetáculo, conforme sua natureza, objetivo e alcance, um plano referente à relação no espaço entre o público e a cena. Estamos falando aqui mais de um modelado do espaço, uma topografia, que favorece ao público entrar em contato comunicativo com a cena. Este é um espaço físico, um suporte arquitetural favorável às condições visuais, auditivas e cinestésicas que promovem esse fenômeno da presença. Espaço que estabelece condições de relação entre a cena e seu público. Espaço de interesse e pertencente ao território da arquitetura, portanto, envolvido em uma linguagem que é própria desse território.

Mas há um outro espaço, que poderia dizer-se, contraposto a esse do sítio arquitetural. Se o espetáculo se dá no encontro, embate entre uma ação cênica e seu público, e se entre os dois existe uma relação de cumplicidade em torno de uma convenção proposta, as diversas imagens oferecidas a esse diálogo pela ação cênica dão origem a um outro espaço. Que é o espaço cênico propriamente dito, próprio de cada espetáculo ou ação cênica proposta e que por serem gerados por um discurso de imagens é essencialmente um espaço imaginário' Temos, pois que diferenciar o espaço suporte, sítio arquitetônico, do espaço imaginário, cênico, particular do espetáculo. Diferenciar, também, sua origem conceptiva: se o arquiteto concebe olugar-suporte, o espaço próprio do espetáculo é concebido pelo encenador. Dois planejamentos com objetivos distintos e, portanto, operando meios distintos ${ }^{2}$

\section{Elementos da Ação Cênica}

Sendo nossa questão central o espaço cênico próprio do espetáculo, é necessário analisar quais são os elementos comunicativos intervenientes na ação cênica, a fim de delimitar o quadro de discursos integrados que formam esse ambiente cênico.

$\mathrm{Na}$ origem de uma ação cênica encontra-se um discurso dramatúrgico. Esta dramaturgia pode ser textual e narrativa, ou chegar ao limite de um roteiro não narrativo, simplesmente denotativo das questōes que a ação apresentará ao público. De qualquer forma a componente dramatúrgica estabelece o ideário e os conflitos que são postos em discussão no espetáculo. O texto dramatúrgico, portanto, é um produto literário, vertido em linguagem verbal, cujo objetivo é embasar o espetáculo. Sendo base, apresenta-se como inacabado para o
(1) "(..) le lieu théatral, ce n'est pas seulement la coquille dans laquelle se situe le spectacle théatral, c'est le cadre mental, la projectionet la réevocation par le spectateur d'une image quia été dans le sprit de l'auteur, dans le sprit du metteur en scène et des acteurs et qui vient ensuite dans l'esprit des spectateurs. II s'agit, par conséquent, d'un lieu essetiellement imaginaire." FRANCASTEL, Pierre. In: Le Lieu Théatral dans la Societé Moderne, org. Bablet, Denis. Paris: CNRS, 1961.

(2) "un des problèmes les plus importants (...) c'est de savoir s'il est jamais possible de faire coincider un leu matériel avec un lieu imaginaire, ce lieu imaginaire étant lui même néces-sairement antérieur au lieu réel qu'il s'agit de construire. Idem. 
(3) BABLET, Denis. Svoboda. Paris: La Cité, 1970. Bablet cita Otomar Kejka: "Le flux de l'image scénique doit agir sur nous comme un ensemble. Peu importe qu'a certains moments nous soyons absorbés par le jeu d'un acteur ou une nouvelle experience vécue que l'auteur a eveillé en nous par un processus formelimprévu, peu importe que notre attention se concentre un instant sur la scénographie et son cinétisme. peu importe qu'a tel moment ce soit l'action musicale qui fasse progresser l'image scénique. ou que justement tout mouvement extérieur apparent s'arrête pour que s'exprime davantage le courant dramatique intérieur. L'important, c'est que l'oeuvre soit menée selon les lois d'un scénario mis en scéne - scénogra phie preparéà l'avance de maniére stricte.

(4) DORT, Bernard. Théatres. Paris: Seuil, 1986. "De nouveaux rapports se sont établis entre la salle et la scéne. Privé de l'illusion de se retrouver comme chezlui au théatre, dans une réalité connue et admise par tous, mais confronté à la realité proprement scénique dujeu théatral, voici le public partagé entre identification et distanciation, libre d'accepter ou de refuser ce langage spécifique que la scéne parle pour lui." Idem - $O$ teatro e sua realidade. São Paulo: Perspectiva, 1977 - "(..) 0 encenador é sem sombra de dúvida um artista. Não apenas o encenador trabalha sobre dados já existentes e em larga medida invariáveis, como o texto e os atores, mas também se dirige a um público preciso e limitado: opúblico do seu teatro." espetáculo, exigindo a integração de outros elementos para a consecução de uma ação cênica.

Se o público presente ao espetáculo tem como condição básica vê-lo e ouvi-lo, a fim de integrar-se em seu processo comunicativo, os elementos visuais se apresentam como uma componente fundamental para, integradas à dramaturgia, construir a ação cênica. Esses elementos visuais são, basicamente, o gesto, o movimento, o ambiente visual. $O$ gesto e o movimento são instrumentos visuais do ator, sendo que o segundo, o movimento, o é, também, do ambiente visual da concepção cênica. Este ambiente visual, extremamente complexo, envolve os elementos construídos, fixos ou móveis; o planejamento colorístico que abrange desde os próprios elementos construídos à cor do vestuário e da maquiagem, incluindo a complexidade dinâmica e expressiva da luz cênica. É evidente, portanto, que são diversos os projetos que, sob o projeto mais abrangente da concepção cênica global, se integram para caracterizar esse ambiente visual: a cenografia com suas construções, os projetos de vestuário, maquiagem e objetos cênicos, o planejamento da iluminação ${ }^{3}$

O ambiente cênico incorpora ainda toda uma gama de elementos sonoros, já que o espetáculo é uma presença visual-auditiva. Nesse campo entram a elocução do ator, seja como fala ou como canto, a música, tanto estruturalmente (no espetáculo musical) quanto formando um envolvimento ambiental, a sonoplastia, trazendo um conjunto de informações sígnicas ao momento cênico. Novamente estamos diante de um conjunto de projetos que, integrados às concepções visuais, incorporam a totalidade da concepção cênica. Deve-se ressaltar o papel do ator que, integrado à concepção abrangente do encenador, desenvolve a construção da personagem através de um projeto complexo que abarca desde o ideário dramatúrgico, o detalhamento de sua elocução, de seu gestual e de sua movimentação de forma integrada.

Devemos, ainda, observar mais um elemento fundamental na construção da ação proposta como espetáculo que é a concepção do sítio cênico. Este, que em uma visão mais apressada parece confundir-se com a cenografia, corresponde a uma proposta, para cada espetáculo, da relação espacial entre o público e a ação cênica. Esta proposta, inserida no projeto próprio do encenador, estabelece se essa relação é de frontalidade, se o público envolve a cena ou se é envolvido por ela, se eles se interpenetram e se fundem.

Pode parecer, também, que esta proposta básica do espetáculo possa já estar determinada pela arquitetura destinada a suportar a cena. Isto tende a ser verdade no caso particular da arquitetura teatral dos séculos 18 e 19, caso se ponham de lado os espetáculos urbanos e a diversidade de formas de espetáculos populares que eram contemporâneos a ela. Já na segunda metade do século 20 se torna nítido que a concepção da relação público-cena se transfere para a mão do encenador ganhando independência, de forma progressiva, da arquitetura que eventualmente se presta como suporte do espetáculo ${ }^{4}$. Por outro lado, a concepção espacial desta relação não se confunde com o projeto cenográfico, posto que este se elaborará a partir dela, conformando o ambiente cênico em função da relação proposta.

É freqüente, também, que a busca desta relação entre a ação e o público, deste sítio cênico, envolva a escolha de um lugar. Ou seja, a determinação de uma paisagem ou de um espaço edificado que, por suas características, concorra com 
dados sociais, formais ou tecnológicos favoráveis à consecução do espetáculo enquanto proposta.

Diante desta análise das concepções que se articulam e se integram no projeto cênico global, podemos reobservar o conceito de cenário es boçado anteriormente. Longe de ser o desenho meramente decorativo de uma construção cênica destinada a ilustrar o discurso do espetáculo, tal como era entendido pelas rígidas ordenações oitocentistas, o cenário deve ser entendido como o próprio ambiente cênico. Envolvendo, portanto, todas as opções e decisões visuais e sonoras que estruturam essa concepção ambiental. Dessa forma a própria cenografia se torna uma das componentes desse ambiente que elabora no quadro dos elementos visuais construídos, que intervém no espaço original de suporte e sugerem nova condição espacial à imaginação do público.

\section{Intervenção no Espaço da Cidade}

Sendo diversos os caminhos por onde se pode abordar a intervenção do espetáculo no espaço urbano podemos observar, por exemplo, como ele se apropria de forma eventual do desenho da cidade, ou como ele estabelece pontos fixos nesse tecido. No recorte deste trabalho esta via é a que mais se insere na questão ambiental em pauta.

São muitas as manifestações cênicas que se apropriam do espaço urbano como suporte. Essa apropriação pode ocupar espaços extensos ou fixar pontos no tecido urbano. De qualquer forma a intenção cênica é catalisar a atenção do público em relação a um espaço transformado sobre o desenho original da cidade. No primeiro caso são manifestações em extensão, móveis, que percorrem trajetos determinados, acompanhados pelo público ou passando por ele. São os préstitos, procissões e desfiles que dramatizam ocasiōes ou comemorações sociais, sejam leigas ou religiosas. Nesse caso o espaço urbano sofre uma transformação operada por engalanamentos, marcos de passagem, plataformas, intervenções musicais e sonoras, efeitos de iluminação. Ocasionalmente, determinados elementos destas intervençōes se tornam permanentes, incorporando-se à arquitetura da cidade, como no caso de arcos triunfais e passos de procissão, ou mesmo sambódromos. O mais freqüente é, no entanto, a ambientação cênica, de forma eventual, de um setor urbano. O que significa uma produção concebida com o objetivo de criar um ambiente limitado ao tempo e presença da manifestação.

A manifestação cênica no espaço urbano também se dá pelo estabelecimento de lugares fixos, favoráveis à reunião com o público, que chegam até a se inserir nos hábitos e costumes da comunidade. Lugares em praças e parques que são adaptados a manifestações musicais, de dança ou dramáticas, ou, mesmo, comícios. Neste caso também se altera, para a presença do espetáculo, o ambiente dessa paisagem particular.

A festa urbana ou o espetáculo em determinado lugar da cidade representam, portanto, uma concepção cênica planejada para intervir e modificar de forma localizada o ambiente urbano para um público determinado e por um tempo restrito a essa presença integrada. Dessa maneira pode se falar de um espetáculo e de um ambiente cênico sobre o suporte urbano e dificilmente pode se alinhar esse conceito cenográfico às imagens espaciais do desenho relativamente permanente da cidade. 


\section{Intervenção no Espaço do Edifício}

Da mesma forma como se analisa o espetáculo e seu ambiente como uma intervenção na cidade, com todas suas características efêmeras e imaginárias, devemos observá-lo como uma intervenção no espaço edificado. O espetáculo, por sua natureza eventual e seu espaço configurado por imagens interativas, se apropria do edifício com uma proposta de alteração efêmera de seu ambiente.

As cidades oferecem, como equipamento, edifícios especialmente destinados à realização de espetáculos, previstos para o encontro entre a ação cênica e seu público. A funcionalidade, a relação espacial entre a cena e a assistência, o apoio logístico à produção cênica, são variáveis que se alteram com a história social e cotidiana de uma comunidade. Mas, como já vimos, para o encenador o edifício é o suporte para uma alteração de caráter eventual, para a criação de um ambiente cênico que intervém no edifício, para o estabelecimento de um cenário e seu espaço imaginário. Portanto, o próprio edifício destinado à realização de espetáculos abriga a permanente possibilidade de alteração em função de um ambiente de imagens cênicas, ambiente que só pertence à natureza do espetáculo.

Este edifício, enquanto equipamento funcional, estabelece em relação ao meio urbano uma referência, um lugar fixo na cidade para a manifestação de espetáculos. Para o encenador, garantida a referência, é um lugar de permanente possibilidade de alteração. Como se ele, lugar edificado, devesse constantemente desaparecer e ceder-se ao lugar imaginário do ambiente cênico.

Sob esse ponto de vista, os encenadores contemporâneos têm tendido a relevar a funcionalidade explícita dos edifícios destinados exclusivamente à realização de espetáculos, já que qualquer proposta cênica envolve a alteração ambiental do espaço edificado. É somente necessário ao encenador que esse espaço edificado ofereça condições favoráveis à sua concepção cênica. Diante de sua ótica, a arquitetura deverá perder seus atributos durante o estabelecimento do ambiente de seu espetáculo. Assim, qualquer edifício pode abrigar um espetáculo desde que suas características reúnam as condições necessárias à proposta cênica ${ }^{5}$.

\section{Intervenção Cênica em Sala da FAU}

(5) DORT, Bernard. Théatres. op. cit. "Non seulement la scéne et la salle à l'italienne ont vécu - on le proclame depuis prés d'un siècle - mais peut être est-ce toute forme fixe de théatre qu'il faut abandonner : toute forme d'architecture préétabie, tout mode d'organisation rigide des rapports salle scène, quitte à définir le lieu théatral comme un lieu vide, totalement malléable, suscetible de prendre toutes les formes possibles et d'être établi n'importe oú (Grotowski prétend avec raison que chaque spectacle nécesite une novelle distribuition des rapports scène-salle)."

\section{Relatório}

Como exemplo da abordagem deste trabalho foi proposta uma intervenção cênica no interior de um edifício com características particulares. A seguir é relatado o planejamento da intervenção, uma breve nota sobre sua realização e um pequeno comentário de seus resultados.

\section{Planejamento}

Data do evento: 29 de junho de 1993

Local: sala 10 do edifício da FAUUSP à rua Maranhão

Roteiro: (em anexo) Intervenção com projeções coloridas alterando o ambiente da sala em questão. O roteiro não inclui nenhuma linha dramática, resumindo-se às projeçōes. Estas se iniciam por um ponto de luz branca (com o objetivo de 
centrar a atenção da assistência) seguido por uma série de projeções coloridas, partindo do azul, passando pelo verde, amarelo e vermelho e voltando ao ponto branco (estabelecendo o fim da intervenção). Entre o amarelo e o vermelho foi inserida a projeção de uma mão espalmada (criando uma imagem de conflito). A leitura do story-board mostra que as passagens foram previstas por intermédio da inserção de sombras e que os movimentos de passagem obedecem a deslizamentos verticais ou horizontais, segundo cada caso.

Equipamentos e materiais: Foram empregados um projetor de slides e um retroprojetor. O ponto luminoso foi preparado com um slide perfurado, para as cores usaram-se filtros rosco para refletores. Para a imagem da mão espalmada foi preparada uma transparência em xerox. Foi previsto tinta vermelha transparente (ecoline) e conta-gotas para um efeito sobre a mão espalmada (este efeito não foi realizado por notar-se, durante o evento, que acrescentaria um componente dramático desnecessário).

Realização: Na sala 10 da FAUUSP/Maranhão escolheu-se centrar os efeitos de luz sobre a parede lateral, precisamente sobre sua porta central, visto que o ponto inicial e outros círculos constantes do roteiro formariam um comentário com o óculo circular que se situa sobre seu batente. Por outro lado, a projeção transversal à sala forçaria a movimentação da assistência em direção à sua direita provocando, de modo algo forçado, seu interesse na reambientação. O projetor de slides e os filtros foram operados por uma única pessoa tomando-se o cuidado de manter um timing propositalmente lento de modo que cada mudança fosse observada e refletida pelos espectadores. As mudanças foram feitas manualmente, ocasionando pequenos tremores e vacilações que não chegaram a prejudicar maiormente a performance. Durante a projeção foi decidido eliminar o efeito citado das gotas vermelhas e seu empastelamento, previsto no roteiro, por perceber-se que se tornariam excessivas diante do efeito da própria mão espalmada que por si já criava o conflito imagético desejado.

Comentário: Pelo fato de que o roteiro não incluía uma linha dramática, resumindose a uma seqüência de cores que alteravam o ambiente da sala, notou-se que diversos espectadores incluíram subjetivamente elementos dramáticos na performance. Por exemplo, incluindo a figura do operador no conjunto do ambiente emprestando-lhe certa conotação inquietante (certamente devido à luz de baixo para cima - contrapino - que iluminava seus movimentos). A imagem da mão espalmada, elemento com dramaticidade implícita, projetada em toda a extensão da parede, provocou diversas reações, desde a afetividade até a ameaça. Foi unânime a sensação de mudança de espaço devido à mudança de cores, se bem que não foi comentado o fato de serem unicamente cores primárias. Prevaleceu a sensação das mudanças sucessivas e do movimento das mesmas. Também foi notada a relação entre as formas circulares projetadas e o círculo que encimava a porta, como mais um elemento de dramatização do espaço da sala.

Estes comentários tentam mostrar que mesmo através de uma intervenção de extrema simplicidade, a alteração do ambiente (por sinal, extremamente familiar aos espectadores) permitiu à assistência criar imagens "dramáticas" ou seja, um espaço de natureza imaginária.

A seguir estão incluídos, além do story-board, uma seqüência de desenhos que ilustram a experiência na ordem em que foi realizada. 


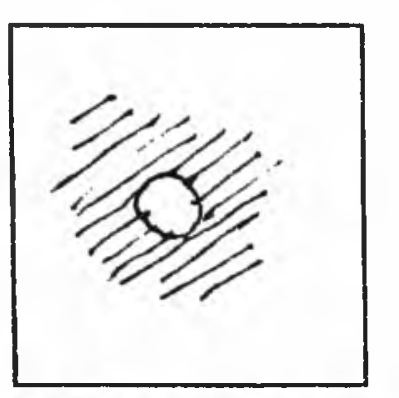

Z. SLIDE DO $2 \pi 0$
APAGA DUI GEAA:

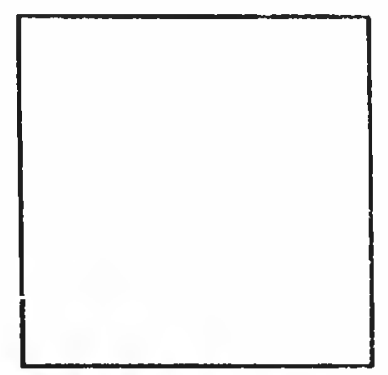

b] [AZUL 1

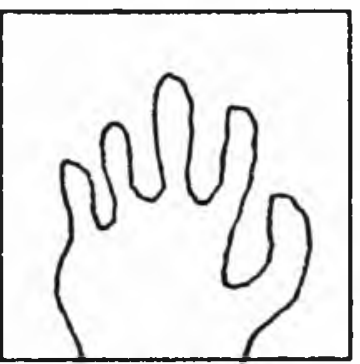

11 [AMAREL I

E. HIDO

L $m$ स 2

(DECIML)

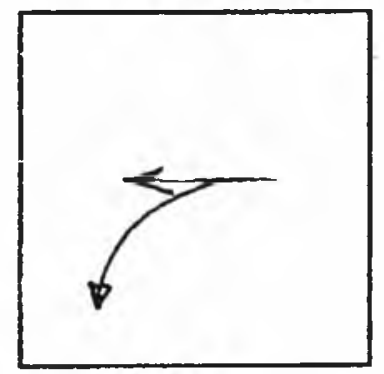

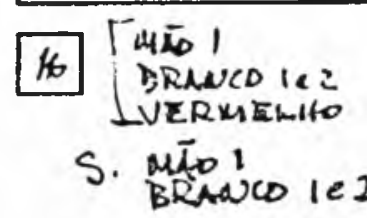

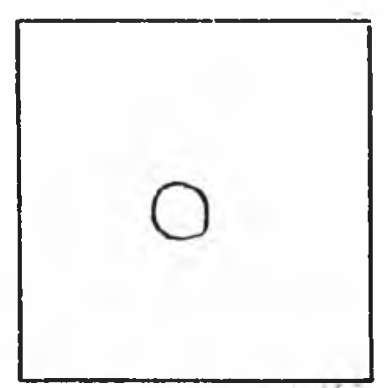

2 [SL.1DE TOUTO 2. KETRO ERAWCO
5. SLIDE DONTD

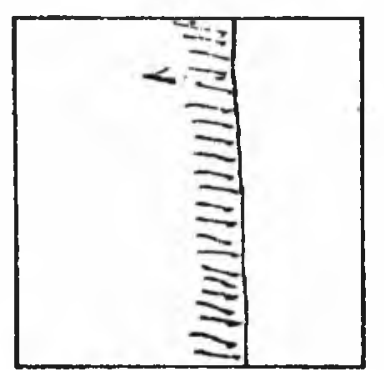

$7]^{[A Z U L}$.

E. [ SOUBAA

5. Schim (imA)

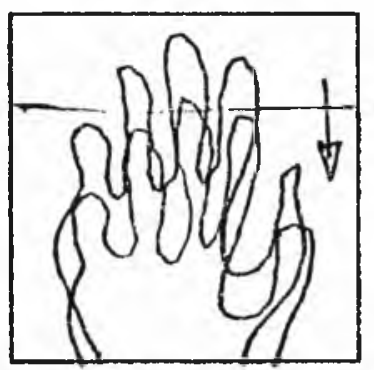

12 amarelo iez

$12]$ LADO $1<2$

S. AMATELOLIL2

Lis 2

E BRANCO 1

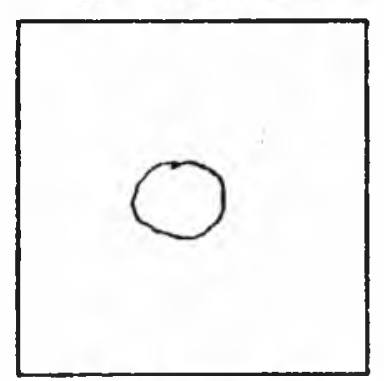

17 LVERAEWHo

I. VEizar. ito:50

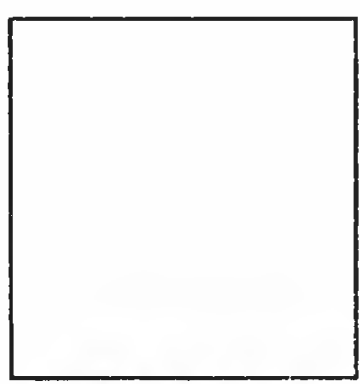

$3]\left[R \pi_{2}\right.$ TRD DRAGCO

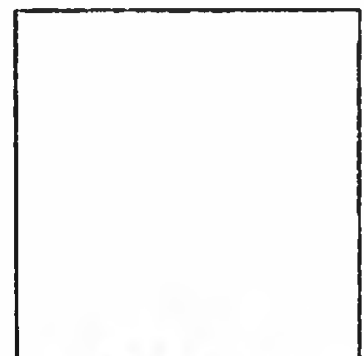

B] $420 \mathrm{OL} 1$

AMIARELOI

(VERDE)

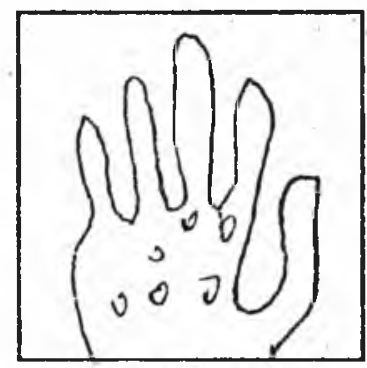

$13\left[\begin{array}{l}\text { MROI } \\ \text { BRANCO } 1\end{array}\right.$

E. FIOUSOSU.

TRAUCD 2

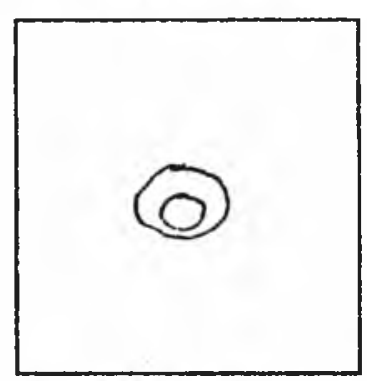

18] [ VERU. PDVID E. SLIDE TOUTO

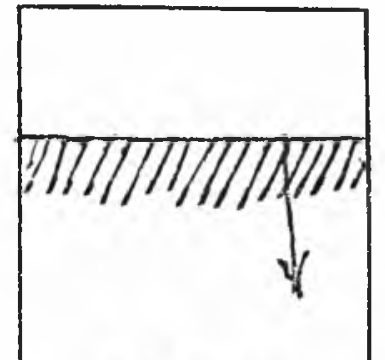

$4]^{\text {E. }}\left[\begin{array}{l}\text { somisina } \\ A z U L 1 \\ A \geq U L 2\end{array}\right.$

S. SOMis2A

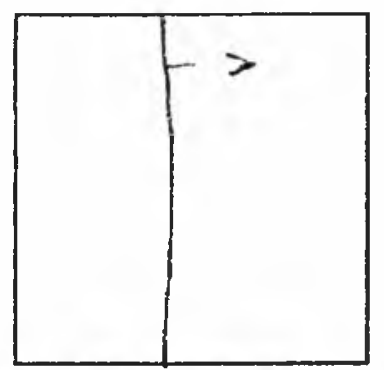

II (VERDE)

5. AzUL 1

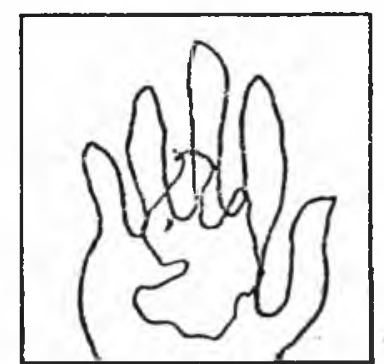

14] MADO 1

LBRAWCO IC2

E. Scuara

s. SOULBDA $(D=\operatorname{Cin} A)$

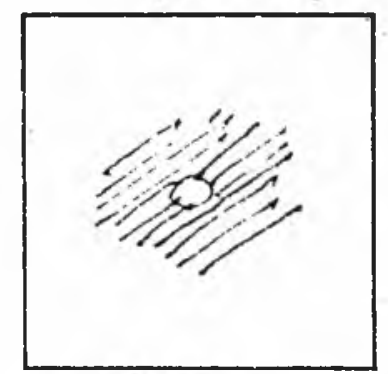

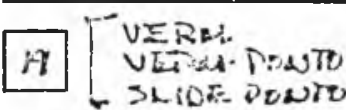
E. SOUDDA Atravir Retion

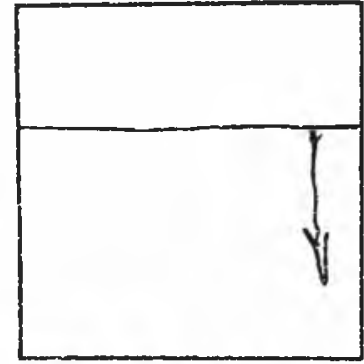

$5]\left[\begin{array}{l}\text { AOUL } 1 \\ \text { AZOL } 2\end{array}\right.$

5. $A Z O L 2$

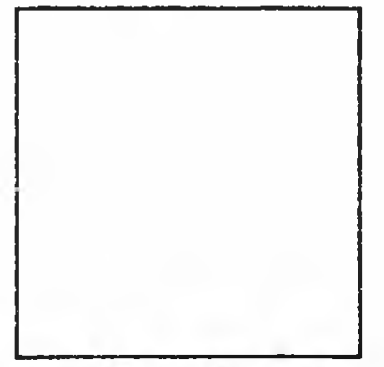

(10] [4ASELO 1 I. AUSDELD 2
(DE CNAS)

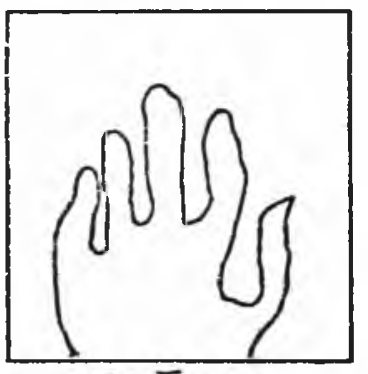

15] पर्ष० 1

15] LRANCD 1:2

E. VERRELHO

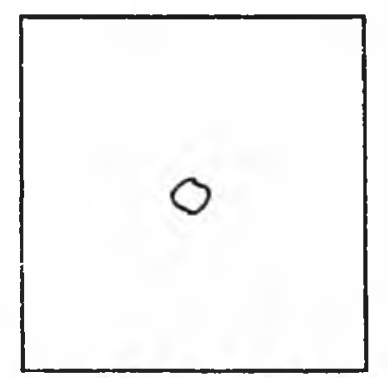
20] SLIDE PONTO APACA SHIDE 

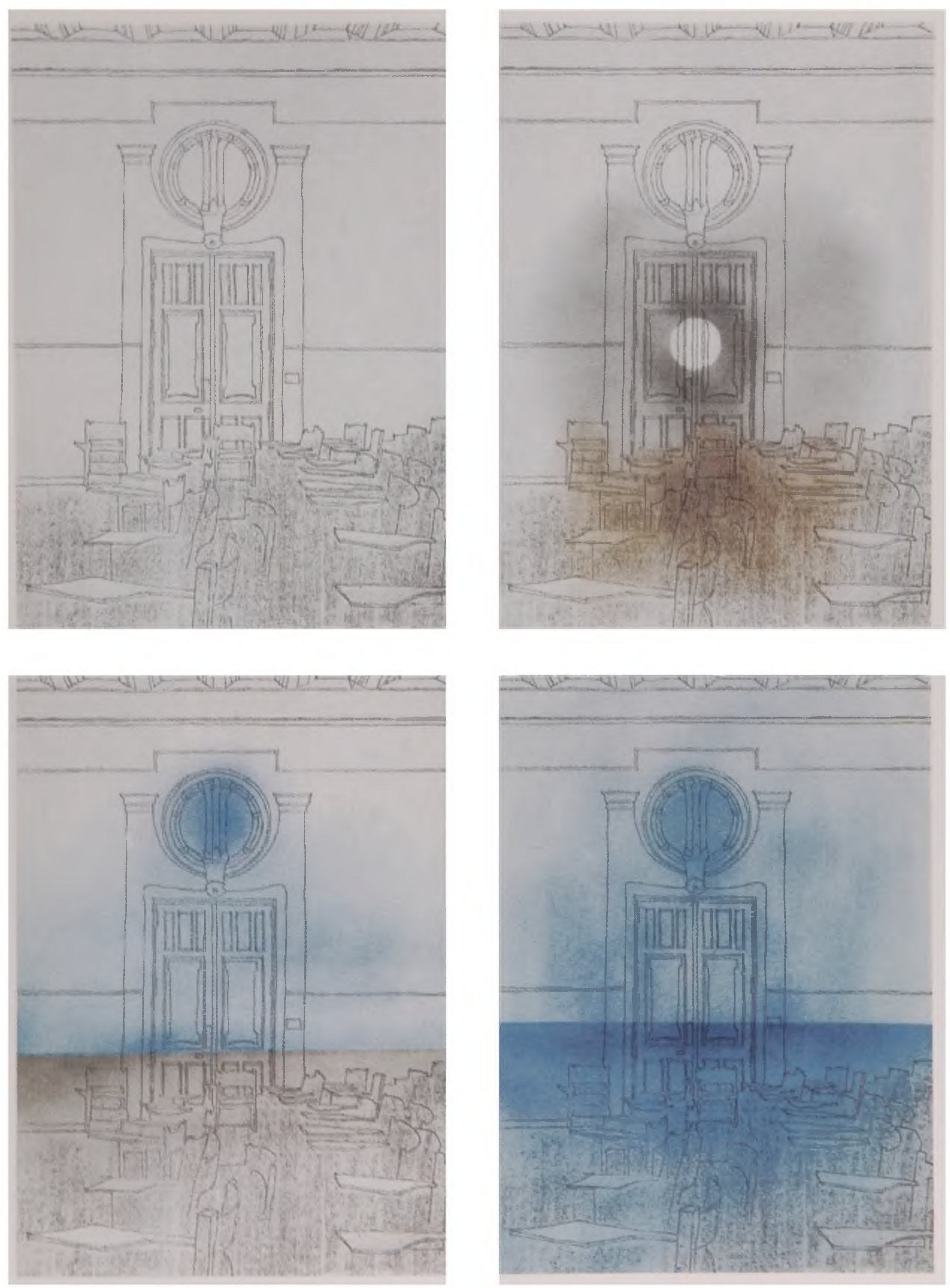

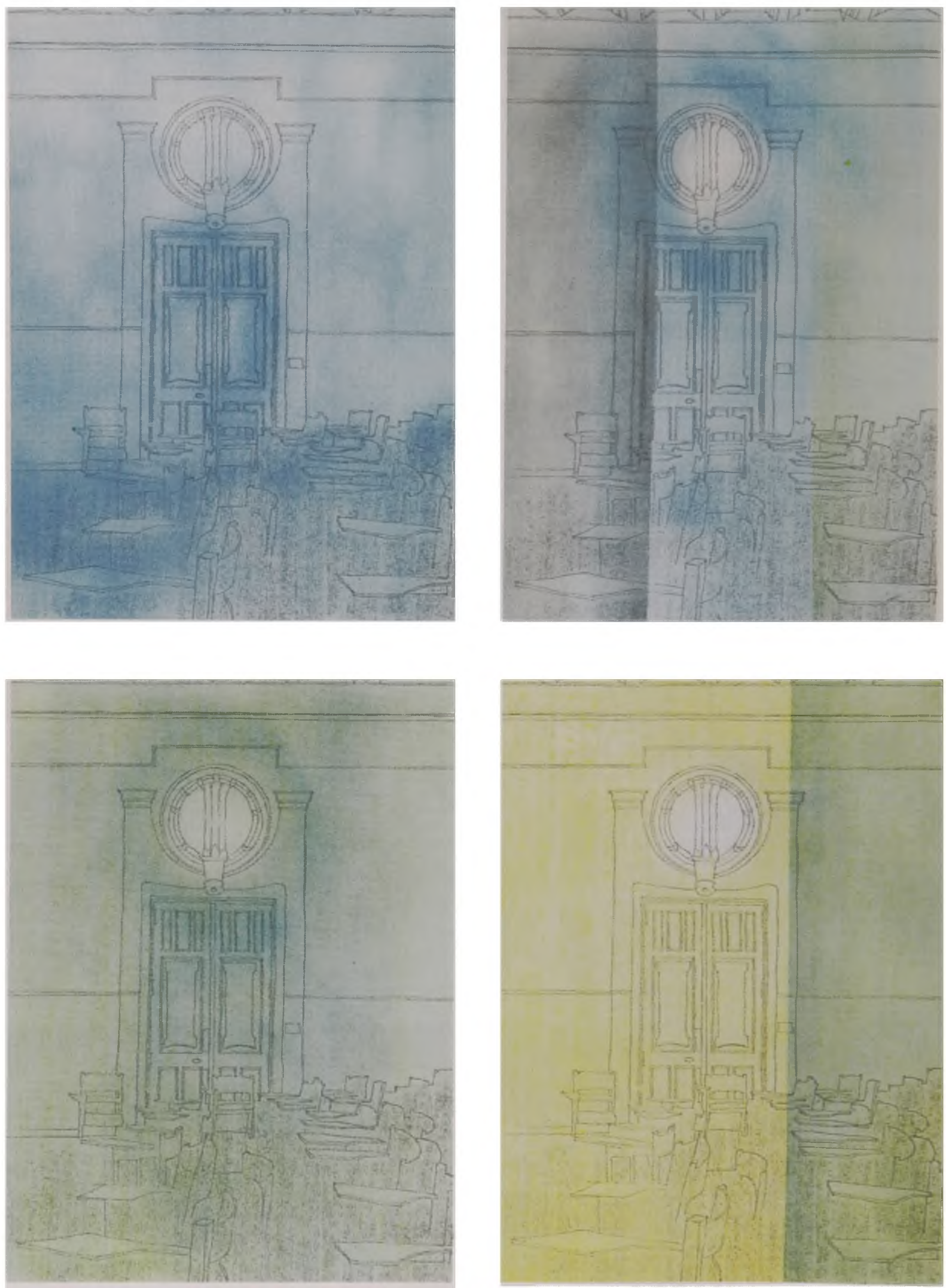

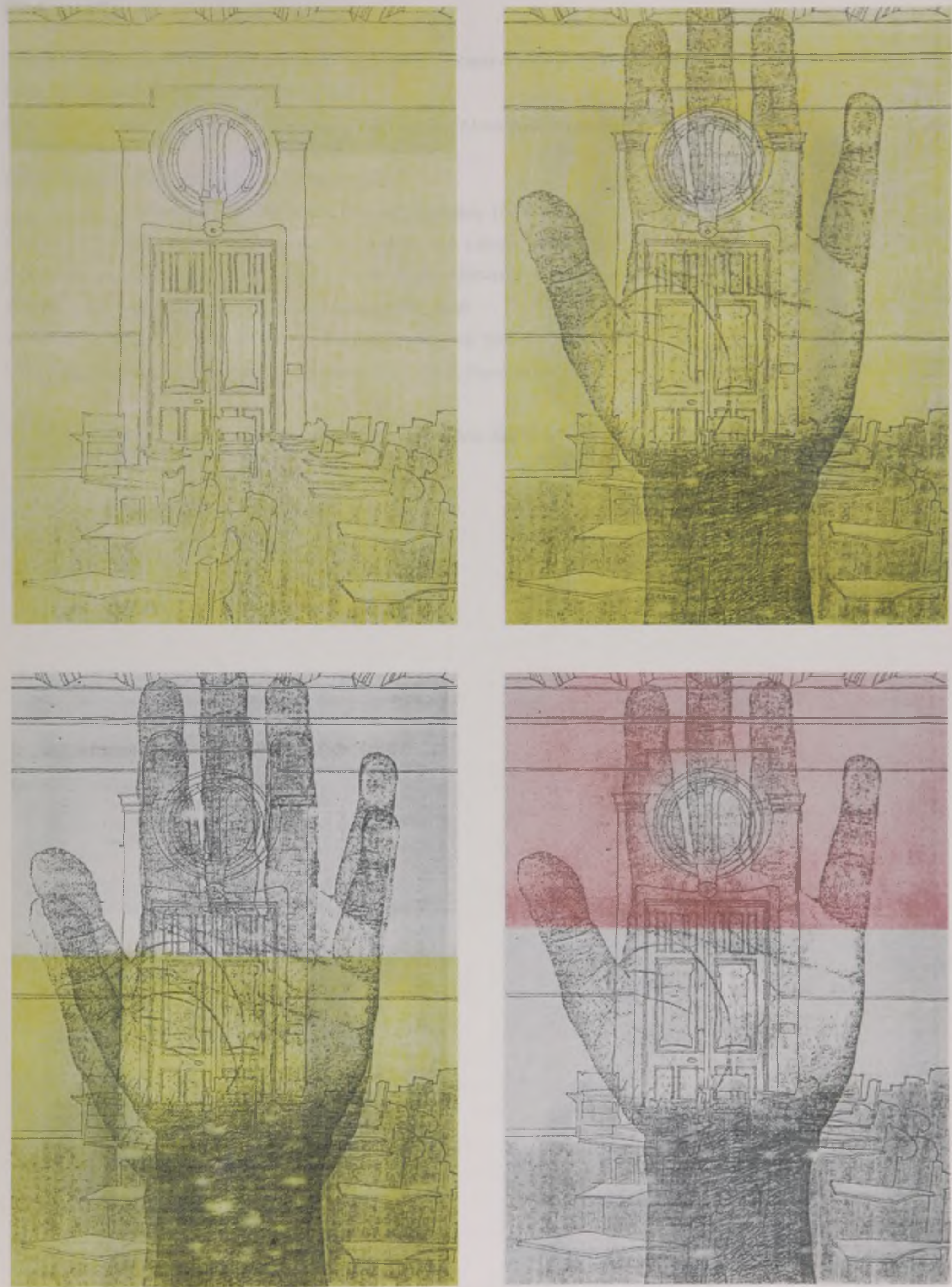

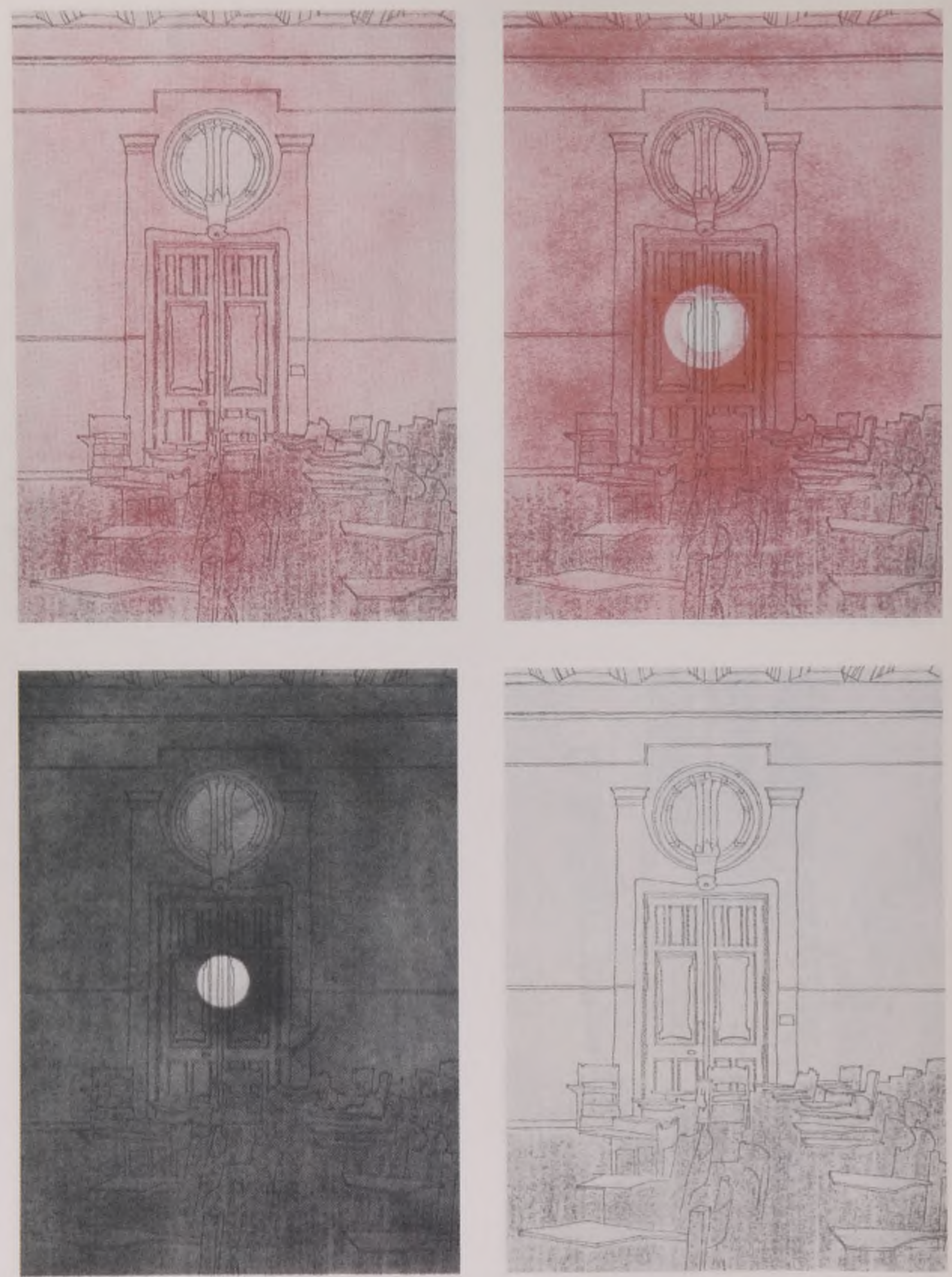


\section{Bibliografia}

BABLET, Denis, JACQUOT, Jean. Le lieu théatral dans la societé moderne. Paris: CNRS, 1961.

BABLET, Denis. Svoboda. Paris: La Cité, 1970.

BENJAMIN, Walter. Obras escolhidas-Oqueé teatroépico?(Umestudo sobre Brecht). São Paulo:

Brasiliense....

DORT, Bernard. Théâtres. Paris: Ed. du Seuil, 1986.

O teatro e sua realidade. São Paulo: Perspectiva, 1977.

GASSNER, John. Rumos do teatro moderno. Rio de Janeiro: Lidador, 1965.

ROUBINE, Jean-Jacques. A liguagem da encenação teatral, 1880-1980. Rio de Janeiro: Zahar, 1982.

ROWELL, Kenneth. Stage design. London: Studio Vista, 1968.

VEINSTEIN, André. La puesta en escena. Buenos Aires: Fabril, 1962.

VILLIERS, André (coord.). Architecture et dramaturgie. Paris: Flammarion, 1950.

* Artigo baseado no trabalho desenvolvido para a disciplina AUP-826 - Mensagens Visuais Integradas $-1^{2}$ semestre 1993. 